\title{
INTERNATIONAL CONTROL OF NARCOTICS
}

\author{
BERTIL A. RENBorG*
}

I

\section{INTRODUCTION}

Narcotic drugs came into widespread use in western medical practice during the latter part of the nineteenth century. They had, in their crude form, been known for their so-called beneficial effects for centuries and had been extensively used, both therapeutically and nontherapeutically, for their calming, intoxicating, and presumed curative properties. Their introduction, however, shortly led to their abuse, and it soon became necessary to try to limit their availability. Accordingly, control mechanisms were early established in most western countries, whose prime objective was the prevention of individual access to these drugs, except by medical prescription. The imperative demand for drugs by the addict and the impossibility of its satisfaction through legitimate channels, however, encouraged the growth of an extensive and lucrative illicit traffic; and if drugs could not thus be obtained domestically, they were procured in foreign countries where control was either nonexistent or less effective. As a result, even the most effective national control was rendered largely nugatory, and the campaign against narcotics abuse came to be recognized as a truly international problem.

It was, in fact, the opium-smoking habit in China that led Theodore Roosevelt, in 1908, to summon to Shanghai the first international gathering for the purpose of planning concerted government action against the abuse of narcotic drugs. It was not, strictly speaking, an international conference, but rather a commission to discuss the problem and recommend possible solutions; and its membership was comprised of those governments within whose far eastern territories opium smoking was a problem. This commission proceeded to lay the groundwork for the first international drug conference, which was held at The Hague and which concluded the first international instrument in this field, generally referred to as The Hague International Opium Convention of 1912.

This convention did not, unfortunately, meet with immediate success; signatures and ratifications were slow in forthcoming before World War I supervened in I914 and halted all progress. The experience was, in fact, so disappointing, that at the war's conclusion, the victorious powers decided vigorously to underwrite the international campaign against narcotic drug abuse. To this end, two steps were taken:

* LL.B. I914, University of Stockholm. Secretary to the League of Nations Commission of Enquiry into the Control of Opium Smoking in the Far East, 1929-30; Chief of the Drug Control Service of the League of Nations, 1939-46; Secretary of the Opium Advisory Committee and the Drug Supervisory Body, I939-46. Author, International Drug Control (I947). 
First, an article inserted in all the peace treaties (e.g., article 295 of the Treaty of Versailles with Germany) provided that ratification of the peace treaties "should be deemed in all respects equivalent to ratification of ... [The Hague] Convention," and further pledged the signatory powers to its enforcement. Secondly, the following article was inserted in the League of Nations Covenant, entrusting to the League the international control of narcotic drugs:

Subject to, and in accordance with the provisions of international conventions existing or hereafter to be agreed upon, the members of the League ... (c) will entrust the League with the general supervision of the execution of agreements with regard to ... the traffic in opium and other dangerous drugs.

During the lifetime of the League, a number of additional international instruments, designed to mitigate the narcotic drug problem, were drawn up and put into execution. These were:

I. the International Opium Convention of I925, which sought principally to regulate international trade and which created the first international organ to supervise and control the application of the convention, the Permanent Central Opium Board;

2. the Convention of July $\mathrm{x}_{3}$, 1931, for limiting the manufacture and regulating the distribution of narcotic drugs;

3. the Convention of 1936 , for suppressing the illicit traffic in dangerous drugs; and

4. the Opium Agreements of 1925 (Geneva) and of 193 I (Bangkok), for gradually suppressing opium smoking.

Moreover, in I940, the Opium Advisory Committee of the League had prepared a draft convention for the limitation of poppy cultivation and the production of raw opium. World War II, however, impeded the translation of this draft into an international convention, and it was abandoned as a basis for further action on this subject by the United Nations, which succeeded the League in this area in 1946 .

In its first ten years, the United Nations has had three new international narcotic drug instruments to its credit. The first was the 1946 protocol on narcotic drugs (Lake Success), by which the League conventions were adapted to the new world organization-i.e., references to League bodies and organs were replaced by those of the United Nations. Second, came the protocol of $x 948$ (Paris), bringing under international control narcotic drugs without the scope of the 193 limitation convention-mainly synthetic drugs that had not been discovered or in use in 193r. Third, there was the protocol of 1953 (New York) for limiting and regulating the cultivation of the poppy plant and the production of, international and wholesale trade in, and use of opium. This last instrument, it should be noted, however, has not yet received the number of ratifications required for its entry into force.

This, then, is the legal structure that governs the international campaign against narcotic drug abuse. It may also be mentioned that the Commission on Narcotic Drugs of the United Nations at present is engaged in drafting a single convention to replace all these existing international narcotic drug instruments, designed to codify, simplify, and strengthen the present system of international control. 


\section{II}

\section{The Pattern of Control}

The objectives of international control can be stated very simply: to prevent the abuse of narcotic drugs, while assuring their continued availability for medical and scientific purposes. To achieve these objectives, the international narcotic drug instruments not only prescribe rules in the international field, but also define the measures of control to be maintained within each country. These two sets of rules are, of course, closely interrelated and mutually interdependent. Thus, effective national control serves not only to prevent abuse at home, but also to protect other countries by stopping the leakage of narcotic drugs into illicit international channels. Again, effective enforcement of all international rules depends on the vigorous cooperation of individual national governments, albeit subject to supervision and control by international organs. In short, there are manifested in these rules the complementary functions of self-protection and the protection of other peoples of the world.

At the outset, it should be observed that these rules were formulated empirically. In I9I2, when the first narcotic drug control instrument was drafted, international cooperation, in general, was in its infancy, and it was then, as later, necessary to proceed slowly, step by step. Experience in the area was either completely lacking or insufficient; there was inadequate technical, medical, and social knowledge of the nature of the problem; and there was no accurate information as to either the extent of the evil or the appropriate measures to combat it. Furthermore, progress in international cooperation has been, necessarily, limited by the agreement of governments; and, accordingly, international legislation, for its widest and most effective appeal, has been forced to seek the most common denominator. In this light, what is the nature and scope of the control mechanisms that have evolved?

\section{A. Internal National Control}

The rule here is very simple. Narcotic drugs in whatever form, either raw, semimanufactured, or 'wholly manufactured and prepared for use, may be handled only by persons or firms licensed for that purpose by competent authorities, and these narcotic drugs may only be purchased for consumption under proper medical prescription. Those authorized to deal with narcotic drugs are required to keep verified accounts of all transactions, and these accounts are subject to regular or ad hoc examination by government inspectors. Physicians, hospitals, and licensed pharmacists, of course, may keep and dispense narcotic drugs without special authorization, but records must be kept and filled prescriptions preserved, subject to inspection. Narcotic drug manufacture may take place only on premises specially licensed for the purpose, and governments are obligated to exercise a strict supervision over factories, narcotic drugs manufactured, and their disposal. Stocks of raw materials in factories may not exceed six months' or, in special circumstances and with special 
authorization, twelve months' requirements. Manufacturers must submit quarterly reports giving a full account of their business, including stocks of raw materials and manufactured drugs on hand at the end of each quarter, to be verified by government inspectors during periodic visits to the factory. Supplies of manufactured narcotic drugs available in each country are limited annually through the operation of the estimates system established by the $193 \mathrm{I}$ convention, the main features of which will be dealt with below. There is, however, no corresponding limitation of raw materials, except that mentioned in regard to supplies in factories, although, if the r953 opium protocol comes into force, there will be limitations on the quantities of raw opium available in each country. Nevertheless, many governments, in enacting narcotic drug legislation, have applied to raw materials the same control measures and restrictions as to manufactured products.

\section{B. Control of International Trade}

At the end of World War I, the international trade in narcotic drugs was the main source of supply for the illicit traffic. Governments in western countries had national control well in hand, but the export and import of raw materials and manufactured drugs were, in general, unrestricted, and they circulated across frontiers and oceans, unhindered, in practically unlimited quantities. In the I920's, this burgeoning international trade began to cause great anxiety, and the League of Nations, therefore, addressed itself directly to this problem. Under its aegis, the I925 convention established a rigid control system, which, in due time, became very effective and which still works well today. Since the success of any international system depends upon the cooperation of the governments that are parties to it, however, this convention, not surprisingly, did not become fully effective immediately, owing to the relatively large number of governments that did not bind themselves to it until a later stage. This untoward situation did, nevertheless, produce an unlooked-for dividend, in that it brought home to the world the fact that success in the campaign against narcotic drugs was only possible on a universal basis-i.e., with the cooperation of all governments and by their acceptance of all obligations under the conventions.

Pursuant to the 1925 convention, the international trade is supervised and controlled by the import certificate and export authorization system. The underlying principle is that in as much as narcotic drugs are dangerous substances, no government may authorize their export to another country without the express consent of the government of that country. This latter must take the form of a certificate stating that the import of specified kinds and quantities of narcotic drugs is authorized and that they are required for legitimate purposes (in the case of raw opium and coca leaves) or solely for medical and scientific purposes (in the case of manufactured narcotic drugs and Indian hemp, or cannabis). The authorization to export narcotic drugs may not be granted until the exporter has submitted to the government such an import certificate issued by the competent authorities of the government 
of the country of destination, and when granted, the authorization must state the number, date, and issuing authority of the import certificate. One copy of the export authorization must accompany the consignment; another must be sent to the appropriate authority of the importing country, which must return its copy to the exporting country when the import has occurred or the time limit for the importation has expired, showing the quantities of narcotic drugs actually imported, if any. Shipments in transit are controlled by the accompanying export authorization and may not be diverted to another destination without a special diversion certificate issued by the exporting country, plus an import certificate from the country to which the shipment is to be diverted. Control of the international trade extends to free ports and free zones in accordance with special provisions. Adherence to these fundamental requirements in international trade is assured by the close supervision of one of the international agencies, the Permanent Central Opium Board, to which each party to the r925 convention must send its quarterly statistics of imports and exports, indicating the country of origin or of destination, as the case may be.

\section{International Limitation of Manufacture}

It soon became apparent, however, that effective control of narcotic drugs demanded that the supply of drugs be geared to the world's requirements for medical and scientific purposes, since any excess tended to find its way into the illicit traffic. World manufacture had to be limited to legitimate needs, and a proposal to this effect was advanced by the United States of America at the 1925 opium conference. When the majority of the participating states refused to entertain this proposal because the matter had not been included in the conference agenda, the United States delegation withdrew and refused to become a party to the convention. The Opium Advisory Committee of the League of Nations took up the matter where the I925 conference had left it, however, and prepared a draft limitation convention that was substantially adopted in I93 I by an international conference that met in Geneva. This convention marked a great step forward and signalized a substantial and bold advance in international law and international cooperation.

The guiding principle of limitation of manufacture, as embodied in the r 93 I convention, is that each country may have at its disposal only the amount of narcotic drugs that it requires for medical and scientific purposes, and that no more drugs may be manufactured than are required to satisfy the legitimate needs of the world. To achieve this goal, the convention binds the parties to determine their requirements for the coming year through the so-called annual estimates, which are then submitted to a special international body set up by the r93I convention, the Drug Supervisory Body, with an explanation of the methods used in their calculation. After examination, the Body establishes the totals of the estimates for each country and territory, which it then publishes in its annual statement of world requirements of narcotic drugs. This is the basic document for limitation of manufacture and use, since the estimates, as set forth therein, are binding on governments and may not be exceeded. 
The convention provides for the possibility of submitting supplementary estimates, if necessary, however, during the course of the year, but governments must explain the circumstances which necessitate the additional quantities. These supplementary estimates, which may, incidentally, be negative, are dealt with by the Body in exactly the same manner as annual estimates, and they are published in supplements to the annual statement.

The Drug Supervisory Body may, except as regards requirements for government purposes, request further information and explanations regarding estimates, but can amend them only with the consent of the government concerned. In case of disagreement between a government and the Body, the latter has no means of action other than publicity, which, however, can be and usually is sufficiently effective. The convention permits the Body to publish in its statements an account of the correspondence or discussions with the government, together with its own observations; and this subtle weapon, or the bare possibility of its use, has been adequate to achieve the purpose of the estimates system-namely, correct and reasonable estimates and the consequent limitation of narcotic drug manufacture and use to the world's medical and scientific needs.

It is obvious that the estimates system, and, therefore, limitation of narcotic drug manufacture and use, can only operate effectively if it is universally applied. With this in mind, the I93I conference sought to provide for governments that would not become parties to the convention and those that would fail to furnish the prescribed estimates. Provisions were, accordingly, inserted in the convention, instructing the Permanent Central Opium Board to request estimates from nonparties to the convention, and the Drug Supervisory Body was given the duty to furnish, itself, estimates so far as possible, if governments, whether or not parties to the convention, failed to do so. The Body has performed this function in innumerable instances, relying on statistics from the past and on other information at its disposal. If a government is dissatisfied with the estimates furnished for it by the Body, it always has the means available to remedy the situation by furnishing supplementary estimates. Estimates established by the Body have the same force and validity as those furnished by governments themselves. They cannot, of course, bind governments that are not parties to the convention (nor, indeed, can government-furnished estimates), but parties to the convention are bound to observe them in their commercial relations with parties and nonparties alike.

If narcotic drug use or manufacture exceed estimates examined and published by the Drug Supervisory Body, the simplest remedies are the furnishing of supplementary estimates or the deduction of the excess from the estimates for the following year. Failing either of these remedies, a violation of the convention has occurred and may result in the invocation of sanctions against the violator, as specified in the provisions regulating the supervision by the Permanent Central Opium Board, dealt with in greater detail below. In consequence, perhaps, the estimates system and the provisions for limitation of manufacture and use, which have been in operation for 
over twenty years (from January I, I934), have produced excellent results. In a few years, world manufacture was brought down very close to medical and scientific requirements. On occasions, manufacture has not even met those requirements, and it has been necessary to supply the deficit from stocks.

\section{III}

\section{Narcotic Substances Under Control}

Generally speaking, all substances which have recognized addiction-producing properties are subject to international control, to a greater or lesser extent. At present, there are four groups of substances which are considered narcotic and which, accordingly, are under general national and international control:

I. opium and its derivatives-i.e., morphine, diocetylmorphine (heroin), codeine, and dionine;

2. coca leaves, ecgonine, and its derivative, cocaine; and

3. Indian hemp drugs (marijuana), now officially referred to as cannabis drugs;

4. synthetic narcotic drugs, which are manufactured by synthesis and capable of producing addiction, but are not obtained directly from raw materials produced by nature, such as opium, coca leaves, or the cannabis plant.

Despite several attempts (particularly during the I93I conference), it has never been possible to arrive at a universally satisfactory definition of narcotic drugs or substances. International legislation has, therefore, resorted to the system of enumerating the substances or groups of substances to be controlled. In the early days, narcotics were described as dangerous substances or drugs, as dangerous habit-forming drugs, or as drugs capable of causing addiction. In some cases, as in the $193^{6}$ convention, which, in its title, uses the words "dangerous drugs," reference is simply made to the drugs and substances to which the provisions of the previous conventions apply. And in others, as in the protocol of 1948, reference is made to drugs which are susceptible to the same kind of abuse and are productive of the same kind of harmful effects as those covered by the I93I convention.

The conventions, of course, obviously had to include provisions to insure international control of additional narcotic drugs not already specifically covered. To this end, therefore, complicated procedures were devised which involve recommendations or decisions by the World Health Organization, assisted by expert bodies. Illustrative are article to of the I925 convention, which refers to any narcotic drug liable to similar abuse and productive of similar ill effects as the substances already falling under the convention; and article II of the I93I convention, which refers to any new product obtained from any of the phenanthrene alkaloids of opium or from the ecgonine alkaloids of the coca leaf. The I93I convention is, thus, more limited, but as both conventions are in force, the provisions of either can be invoked. The decisions of the World Health Organization in this context, under the r925 con- 
vention, it should be noted, are only recommendations which parties may or may not accept; those under the I93I convention and under the I948 protocol, however, are binding on the parties.

The I948 protocol, incidentally, had to provide a special procedure, as it was intended to extend to any narcotic drugs not otherwise under international control. It leaves the initiative with the governments, through notifications to the SecretaryGeneral of the United Nations. The World Health Organization then has to decide whether the substance in question is capable of producing addiction or of conversion into such a product. If the decision is affirmative, parties to the protocol are bound to apply the appropriate provisions of the I93I convention. Pending the decision of the World Health Organization, however, the Commission on Narcotic Drugs of the United Nations has the power to decide, with binding effect for the parties, that the controls of the I93I convention shall be applied provisionally. The procedures for bringing additional narcotic drugs under international control are lengthy and cumbersome, since it may require a year or more for the World Health Organization to make the investigations and experiments necessary to its decisions. It is for this reason that both the r 93 I convention and the 1948 protocol contain rules for temporary control measures pending final decisions.

\section{IV}

\section{The Principal Organs of Control}

International supervision today derives its authority partly from the Charter of the United Nations and the decisions of its Economic and Social Council, but mainly from the international conventions and agreements. The supervision is exercised through a number of different organs, of varying composition and function.

\section{A. The Commission on Narcotic Drugs}

The United Nations Charter makes no specific reference to narcotic drugs, but these fall under the provisions for international cooperation in solving problems of an economic, social, cultural, or humanitarian character, referred to in article I, paragraph 3 of the Charter. By virtue of this wide competence, the Economic and Social Council, in February 1946, moved to take over narcotic drug control from the League of Nations by establishing its Commission on Narcotic Drugs. The resolution which contains the terms of reference and defines the competence of this commission reads as follows:

\section{Commission on Narcotic Drugs}

r. The Economic and Social Council, in order to provide machinery whereby full effect may be given to the international conventions relating to narcotic drugs, and to provide for continuous review of and progress in the international control of such drugs,

Establishes a Commission on Narcotic Drugs.

2. The Commission shall:

(a) assist the Council in exercising such powers of supervision over the application 
of international conventions and agreements dealing with narcotic drugs as may be assumed by or conferred on the Council;

(b) carry out such functions entrusted to the League of Nations Advisory Committee on Traffic in Opium and other Dangerous Drugs by the international conventions in narcotic drugs as the Council may find necessary to assume and continue;

(c) advise the Council on all matters pertaining to the control of narcotic drugs, and prepare such draft international conventions as may be necessary;

(d) consider what changes may be required in the existing machinery for the international control of narcotic drugs and submit proposals thereon to the Council;

(e) perform such other functions relating to narcotic drugs as the Council may direct.

3. The Commission may make recommendations to the Council concerning any subcommission which it considers should be established.

4. The Commission shall be composed of fifteen Members of the United Nations, which are important producing or manufacturing countries or countries in which illicit traffic in narcotic drugs constitutes a serious social problem. The term of office of members is three years. They are eligible for re-appointment.

5. The Commission is authorized by the Council to appoint in a consultative capacity, and without the right to vote, representatives of bodies created under the terms of international conventions on narcotic drugs.

6. The Council requests the following Governments to designate one representative each to constitute the Commission:

$\begin{array}{ll}\text { Canada } & \text { Peru } \\ \text { China } & \text { Poland } \\ \text { Egypt } & \text { Turkey } \\ \text { France } & \text { United Kingdom } \\ \text { India } & \text { United States of America } \\ \text { Iran } & \text { Union of Soviet Socialist Republics } \\ \text { Mexico } & \text { Yugoslavia } \\ \text { Netherlands } & \end{array}$

It will be seen that the competence of the Commission is very extensive and relates to the past, present, and future, but the Commission, like its predecessor, the Opium Advisory Committee of the League of Nations, is, in general, an advisory organ to the Economic and Social Council. In principle, therefore, its decisions are subject to confirmation or approval by the Council, except in cases where the Commission has been given specific functions by the conventions. The single convention, as presently drafted, may confer on the proposed International Narcotics Control Board a series of independent functions not subject to the review or approval of the Council, but this, of course, is a matter for the future.

By means of an extensive system of informational exchanges and reports, the Commission on Narcotic Drugs is constantly kept in touch with situations as they develop and can take timely remedial measures when required. More specifically, the conventions impose on governments the obligation of transmitting to the Secretary General the following series of reports and information: 


\section{Laws and Regulations}

All conventions, from rgr2 up to and including the 1953 protocol, provide that the parties shall communicate to one another, through the Secretary General, the text of laws and regulations promulgated to give effect to the conventions. These documents are translated by the United Nations Secretariat as and when necessary and circulated to governments and to the Commission on Narcotic Drugs. The Narcotics Division of the secretariat also has annually submitted to the Commission a summary of these laws and regulations, making it possible for both governments and the Commission to follow legislative developments without any reference to long and complicated texts. At its last session (I956), the Commission abolished this annual summary and decided that it should only be produced every five years. There will, however, be an annual cumulative index, an annual tabulation of changes in the scope of control, and, as the need arises, analyses or studies of particular aspects of control. These decisions were taken under the impact of a resolution by the Economic and Social Council concerning the reduction of the United Nations documents in general. The wisdom of abolishing the annual summary is, however, questionable.

\section{Annual Reports}

The system of annual reports was instituted at an early date by the League of Nations and was made an obligation through the r93x convention. In fact, annual reports are also provided for in the subsequent conventions and the r953 protocol. In the terms of the x93I convention, parties shall forward to the Secretary General an annual report on the working of the convention in their territories, in accordance with a form drawn up by the Commission on Narcotic Drugs. This form is very elaborate and covers all aspects of narcotic drug control, illicit traffic, and addiction. The annual reports received are analyzed by the secretariat and incorporated in an annual summary, which is discussed in detail by the Commission. These reports afford an excellent means by which both governments and the Commission may follow developments all over the world and discuss and try to remedy weaknesses and gaps in international narcotic drug control.

\section{Reports on Cases of Illicit Traffic}

The Opium Advisory Committee of the League of Nations, in the early days, had already asked governments to transmit, for examination, reports on significant cases of illicit traffic, and the 1931 convention gave a treaty basis to this practice. Article 23 of this convention requires the parties to communicate to each other, through the Secretary General, as soon as possible, particulars of illicit traffic which may be of importance either because of the quantities involved or because of the light thrown on the sources or on the methods employed by the traffickers. These reports are periodically communicated to governments in summarized form and form the basis of the discussions on illicit traffic by the Commission on Narcotic Drugs. 


\section{Reports on Manufacturing Industries}

Article 20 of the 193I convention made it a binding obligation upon governments to inform each other, through the Secretary General, of all establishments authorized to manufacture narcotic drugs, a practice that had already been established by the Opium Advisory Committee of the League. Detailed information must be supplied, with names, addresses, kinds of narcotic drugs manufactured or converted, as well as any changes in the authorization or cessation of manufacture. The information thus received by the Secretary General is communicated periodically to both governments and the Commission on Narcotic Drugs in the so-called list of drug factories.

\section{Reports on Authorities to Issue Import Certificates and Export Authorizations}

In order that the system of import certificates and export authorizations may function satisfactorily and in order to avoid fraud, it is necessary that the names of the authorities issuing these documents be known. For national control, it is essentral that only one central authority issue these documents. Governments are required to furnish this information in their annual reports, and the secretariat of the United Nations publishes periodically a list of these authorities.

When the United Nations appointed its technical or functional commissions, it decided to keep them small in order to save time and make them work as efficiently as possible. Furthermore, states not members of the United Nations were excluded. By way of contrast, at least in regard to narcotic drugs, the League of Nations adopted a different philosophy, arguing that any state, whether or not a member of the League, which so desired, should be permitted to participate in the work of the Opium Advisory Committee. Not surprisingly, therefore, the Committee had no less than twenty-five members. The Commission on Narcotic Drugs has felt increasingly the need for cooperation with unrepresented states, however, and has, accordingly developed a system of inviting such states to assist it at its sessions as observers who may not vote, but who may take part in the deliberations. States may also send observers to the meetings without an invitation. This system has developed to such an extent that at the eleventh session (1956), not less than seventeen states had either been invited to attend or attended as observers, in general or for specific questions. This would seem to indicate that the membership of the Commission is too restricted. Moreover, continuity and technical knowledge are of paramount importance and can only be guaranteed by a more or less permanent participation in the work. The Commission should, of course, also have adequate geographic representation for the various regions of the world, and this is hardly the case today when only two Latin American states out of twenty are represented, and the Far East and Africa have only one representative each.

With respect to working methods, the Commission on Narcotic Drugs has not, so far, developed a system of working through permanent or ad hoc subcommittees. or of using its own experts. Following the League precedent, however, there has been, for the past two years, a permanent subcommittee on the illicit traffic that 
meets for a few days before each session of the Commission and submits a considered report to the Commission itself. The Opium Advisory Committee of the League, on the other hand, had a number of permanent subcommittees (e.g., agenda, illicit traffic, cannabis, limitation of opium production, and list of drugs falling under the conventions) as well as a staff of permanent experts on specific subjects (e.g., illicit traffic, cannabis, and limitation of opium production) called assessors.

Preparation of questions by small subcommittees would insure a more focused application of expert knowledge to all aspects of a problem, and, above all, it would facilitate and shorten the discussions of the Commission itself. It also would tend -and this is important-to eliminate excessive influence on decisions in technical fields by political and other sometimes irrelevant considerations. Experience has proved that a commission in plenary session is, on the whole, likely to accept the agreed conclusions arrived at by its subcommittee, and as subcommittees meet in private, there is a much freer exchange of views and opinions than is possible in public meetings.

The Commission on Narcotic Drugs has, on occasions, had recourse to experts, but these have usually been experts of other international organizations, such as the Food and Agriculture Organization and the World Health Organization. A typical instance of this were the inquiries regarding cannabis, which were initiated by the Commission and carried out by the Food and Agriculture Organization. It is, of course, quite logical to apply to other international organizations for expert assistance within their special competences, but this procedure has two distinct drawbacks. First, the other organizations have their own work to consider and usually have neither the funds nor the personnel to devote to what might be called outside work. Secondly, these organizations cannot possibly possess the general and specific knowledge of the narcotic drug problem which is indispensable in technical inquiries. The secretariat of the Commission naturally insures planning and coordination, but its influence is limited. Better and quicker results would be obtained if the experts worked directly under and for the Commission, at its expense.

With its present composition and working methods, the Commission on Narcotic Drugs makes but slow progress-in fact, too slow. It spent years on a draft convention for limiting raw opium production, only to discard the whole draft in 1952 and substitute for it a draft which later became the 1953 protocol. The single convention has been under elaboration for over six years, and is not yet anywhere near the final stage-a situation at least partly owing to the Commission's lack of both effective subcommittees and its own qualified experts.

But even apart from the slowness of its progress, further developments of the Commission on Narcotic Drugs are seriously hampered by the fact that political considerations play such a large role in its work. This may, to some extent, be attributable to the uneasy international situation as a whole, but it is obvious that there is not, in the Commission, the same concern with the general interests of humanity that existed in the Opium Advisory Committee of the League. In the League, 
the work after the first few years was entirely motivated by technical and humanitarian considerations; today, national economic interests make themselves felt, and the political cleavage between West and East exercises considerable influence. Illustrative is the way in which the Commission, at its 1956 session, dealt with the situation on the mainland of China. In previous years, there had been long and serious discussions of the notorious fact that the mainland of China is the largest producer of opium in the world (all illegal production) and that heroin and morphine manufactured therefrom in large quantities find their way into the illicit traffic in the Far East and thence to the West. At the 1956 session, however, the representative of the United States did not furnish the detailed information about the situation that he had given in previous years, and the Commission's report deals with the situation very lightly and almost incidentally. It was also apparent that the representatives of certain other governments had been instructed not to enter into any serious discussions of the situation and not to level accusations against the Peoples Democratic Republic of China. Whatever the political considerations might have been, however, they should not have been allowed to interfere with the campaign of the Commission against the illicit traffic; and there can be no doubt that the situation on the mainland of China is the most serious and difficult aspect of the narcotic drug problem that confronts the world today.

\section{B. The Permanent Central Opium Board}

This Board was set up by the 1925 convention, and its task under that convention is continuously to watch the course of the international trade to prevent narcotic drugs from escaping into the illicit traffic. The Board has broad powers of intervention and may recommend an embargo on further exports of narcotic drugs to any country if information at its disposal leads it to conclude that excessive quantities of narcotic drugs are accumulating there or that the country is in danger of becoming a center of illicit traffic. These broad powers of the Board are circumscribed by a number of safeguards, however, such as the requirement of a previous demand for explanations, the right of the country concerned to be present at the Board's discussions, the provision for notifications to all parties to the conventions and to the Economic and Social Council, and right of the country concerned to bring the matter before the Economic and Social Council.

The information at the disposal of the Permanent Central Opium Board consists of annual and quarterly statistics of all drug transactions, which parties are obliged, under the convention, to transmit to it. Nowadays, the Board also takes cognizance of and may use annual reports submitted by governments to the United Nations and of their reports on cases of illicit traffic.

The Permanent Central Opium Board acquired additional coercive functions under the r93I convention. In certain cases, its recommendation of embargoes, as authorized by the 1925 convention, became real embargoes which parties to the convention were obligated to apply. For, if it appears from the quarterly import and 
export statistics or from certain notifications made to the Board that the quantities of narcotic drugs exported or authorized to be exported to any country or territory exceed the total of the estimates for that country or territory, the Board must immediately apprise all parties to the convention, who may not then, during the year in question, authorize any further exports to the country or territory involved, subject to two exceptions: if the situation is regularized by supplementary estimates, or, in exceptional cases, if the government of the exporting country considers further exports essential in the interest of humanity or for the treatment of the sick. Otherwise, however, there is no recourse against this embargo, either by the country concerned or by parties to the convention; its application is quite automatic. As the Board meets only twice a year, the secretariat is authorized to impose such embargoes when the Board is not in session. It goes without saying, of course, that this sanction will not be used by the Board in cases where the excess is small and probably attributable to oversight or faulty accounting. Then, the Board will limit itself to directing the attention of the country concerned to the excess and suggesting that the excess should be covered by a supplementary estimate. It is of interest to note that an embargo under these provisions may also be imposed by the Board against a country which is not a party to the convention.

The second new function acquired by the Permanent Central Opium Board under the I93I convention was the preparation of an annual statement, on the basis of government statistics, showing the extent to which governments have observed their obligation to remain within their estimates. This is an annual balance sheet, showing, on the one hand, the estimates, and on the other, the narcotic drugs consumed, manufactured, converted into other substances, or compounded into certain preparations, imported, and exported. If it should appear that a party has or may have failed to honor its obligations under the convention, the Board has the right to recommend the imposition of an embargo against such party, in accordance with the provisions of the I925 convention. The statement on which the embargo is based must be published by the Board as soon as possible, with such explanations and documents as the Board may wish to include.

These are the main powers and functions of the Permanent Central Opium Board which, in fact, is a semijudicial organ, passing judgment on the manner in which governments acquit themselves of their conventional obligations and recommending or applying sanctions in appropriate cases.

The Permanent Central Opium Board is composed of eight persons, appointed in their personal capacity by the Economic and Social Council for five-year periods. The I925 convention specifies the qualifications of the members of the Board: they shall, by their technical competence, impartiality, and disinterestedness, command general confidence, and they must not hold any office which puts them in direct dependence on their governments. The convention also provides that members shall, in equitable proportions, consist of persons possessing knowledge of the narcotic drug situation, both in producing and manufacturing countries on the one hand, and in the 
consuming countries on the other. The Board is, thus, an independent organ that carries out the functions with which it has been charged by the I925 and r93I conventions.

The Permanent Central Opium Board has now performed its duties for more than a quarter of a century. It has kept strictly within its functions, as defined by the conventions. The work, which is largely statistical, has been done painstakingly, but cannot be very inspiring. On occasions, members have found it impossible to attend sessions of the Board, perhaps through lack of sufficient interest. The secretariat of the Board has, in some cases, assisted governments in improving their statistical information and administrative services. This is a useful activity which could, with advantage, be extended, subject to requests from governments.

\section{The Drug Supervisory Body}

The functions of the Drug Supervisory Body, which was set up by the x93I convention, have already been outlined above in the discussion of limitation of manufacture. The Body consists of four members, two appointed by the World Health Organization, one by the Commission on Narcotic Drugs, and one by the Permanent Central Opium Board. The convention does not specify the qualifications of the members, but the nature of the appointing bodies insures at least certain significant special competences (e.g., medical knowledge and knowledge of narcotic drug control). The annual and supplementary statements on world narcotic drug requirements, prepared by the Body, form the keystone of the system of limitation of manufacture and of quantities of manufactured narcotic drugs available in each country and territory of the world. The work of the Body, in this connection, through the years (it was established in I933), has been very useful and effective. It has acquired great authority and has been instrumental in reducing to reasonable proportions government estimates which, for reasons of safety, have tended to exaggerate legitimate needs-a tendency which, if unchecked, would naturally have resulted in manufacture in excess of world requirements and in the building up of unnecessarily large stocks that might have escaped into the illicit traffic.

The Drug Supervisory Body will assume further and similar functions in regard to opium estimates under the 1953 protocol. But if the single convention, as presently drafted, comes into force, the Drug Supervisory Body and the Permanent Central Opium Board will be combined into a single organ, the International Narcotics Control Board. This attempt at simplification may not be an entirely happy one, however, in light of the strikingly different functions of the constituent organs. The Drug Supervisory Body determines, by its examination of estimates, maximum permissible national and world narcotic drug totals. This, for the Permanent Central Opium Board, is the starting point, both in its supervision of the application of the conventions by governments and for its possible invocation of sanctions. The International Narcotics Control Board would, thus, in a manner, function as both prosecutor and judge. 


\section{World. Health Organization}

As narcotic drug addiction is a medicosocial problem, it is quite fitting and proper that the World Health Organization should be concerned in its resolution. As has been noted, it appoints one member of the Drug Supervisory Body and has a very important role to play under the 1925 and I93I conventions and the 1948 protocol in the mechanism for putting new narcotic drugs under control or removing them from control. It has a special drug section in its secretariat and carries out its investigations through an expert committee on drugs liable to produce addiction. It will, in the future, be concerned with the revision of the list of drugs falling under the international narcotic drug treaties and has, for this purpose, enlisted the help of a small group of experts.

Another important task of the World Health Organization is the establishment, in cooperation with governments, of international nonproprietary names of narcotic substances. As a rule, narcotic drugs are placed on the markets with fancy and unintelligible names given them by manufacturers or wholesalers. More often than not, the name does not reveal the fact that the drug is a narcotic substance, and there is a grave risk of such drugs being used unwittingly, without the necessary safeguards. Its procedure, in this connection, is, however, rather slow, and the Commission on Narcotic Drugs, at its last session, instituted an investigation for evolving an alternative or supplementary procedure that would be simpler and quicker.

The World Health Organization is, at present, also carrying out a very important series of investigations concerning methods for curing and rehabilitating addicts, and with its high scientific and technical standard, it is making a very useful contribution in this area.

\section{$\mathrm{V}$ \\ The Major Problems of Control}

\section{A. Suppression of the Illicit Traffic}

The suppression of the illicit traffic is one of the primary objectives of the campaign against the narcotic drug evil, and the principal international organs devote much attention to this matter. The Opium Advisory Committee of the League was seriously occupied with the illicit traffic, which, in the 1920's and 30 's, was formidable. The secretariat of the League proved to the I93I conference, on the basis of statistics of manufacture and of imports and exports, that enormous quantities of narcotic drugs, especially heroin and morphine, had disappeared into the illicit traffic from stocks manufactured by licensed establishments. There were other alarming disclosures as well. Certain governments, not parties to the r925 convention and, thus, not obliged to adhere to the system of import certificates and export authorizations, had-probably in ignorance of the consequences-licensed a number of factories from which a steady stream of narcotic drugs flowed into the illicit traffic. And infamous traffickers in Western Europe, whose lucrative dealings had been snuffed out in 
their own countries by the vigorous application of the 1925 convention, had moved their factories and businesses to countries where narcotic drug control was slack or nonexistent.

The Opium Advisory Committee, nevertheless, made short shrift of all these nefarious activities. On the basis of illicit traffic reports and information furnished by its members, the Committee, at every session, thoroughly studied and discussed the traffic and exposed the trends, the origin of drugs, and the methods employed. It uncovered and put out of business the wealthy and powerfully organized international bands of traffickers, organized close cooperation between enforcement agencies in various countries, and repeatedly recommended heavier sentences as the only effective deterrent. Moreover, the Committee reviewed at every session the situation in particular countries which appeared to be either centers of illicit traffic or its victims. In furtherance of this activity, there was a permanent subcommittee on illicit traffic, where the detailed discussion took place and where many countries participated with their specialists.

Finally, a special international convention was prepared and concluded at a conference in Geneva in 1936, for the suppression of the illicit traffic in dangerous drugs. Its main purpose was to organize close international cooperation against illicit traffic and to provide sufficiently severe penalties for offenses (e.g., imprisonment or other penalties of deprivation of liberty, fines, and confiscation of drugs and instruments -for instance, aeroplanes and motor cars-used by traffickers). Similar penalties applied to intentional participation, conspiracy attempts, and preparatory acts, and there were further provisions designed to punish offenders who engaged in illicit traffic in countries other than the ones in which they resided. The convention made extradition obligatory, with retroactive effect, and directed that each party establish a central office for the suppression of the illicit traffic, which should keep close contact and correspond directly with the central offices of other countries. This convention, however, has not, so far, had the same general application as the previous conventions. Only twenty-two countries have become parties, the explanation probably being that many states with negligible or nonexistent illicit narcotic drug traffic have not felt it incumbent on them to ratify a convention that would involve them in complicated legislation and administrative measures.

The United Nations has continued the campaign against the illicit narcotic drug traffic along the same general lines as did the League of Nations. Although this traffic remains very active in many parts of the world-the most important centers today being the Near and the Far East-the Commission on Narcotic Drugs has not, unfortunately, dealt with it as effectively and as ruthlessly as did the Opium Advisory Committee. There has been a discernible tendency to soft-pedal criticism in order to save the national pride of certain governments; there has not been the same frank publicity concerning unsatisfactory conditions. The United Nations, in fact, no longer functions as clearing house for uncovering and pursuing the illicit narcotic drug traffic, a task that has largely been assumed by the International Criminal Police 
Commission, of Paris, an international government organization for the suppression of fraud and criminality. This latter commission operates in close collaboration with the Commission on Narcotic Drugs, however, and attends its discussions on illicit traffic.

\section{B. Narcotic Drug Addiction}

Drug addiction, its prevention and cure, has not, as yet, received the international attention it deserves. Neither the League nor the United Nations has progressed very far in this field, except, incidentally, as a by-product of activities designed to prevent narcotic drugs from reaching the addict. Addiction is a medicosocial problem, closely connected with the economic and social conditions under which people live and work. Apart from mitigating predisposing economic and social conditions, however, there are other techniques for inhibiting addiction, the most significant of which is education. But antinarcotics education has been banned both by the League and by the United Nations, except in countries where addiction is adjudged a serious problem and among the medical and paramedical professions. Few countries, however, are willing to admit that domestic drug addiction constitutes a serious problem and the argument is also raised that antinarcotics education may draw to the subject the attention of those who may previously have been unaware of the narcotic drug problem and who may subsequently be tempted to try drugs out of curiosity. Such cases may, of course, conceivably occur, but even so, they would hardly counterbalance the number of potential narcotic drug users who might be saved if they were fully apprised of the fateful results of addiction.

The existing international attitude towards this problem is obsolete, particularly in the more developed countries, where the standards of living and education and, therefore, also the sense of responsibility are constantly rising. Accordingly, this is a problem concerning which the Commission on Narcotic Drugs should institute a thorough inquiry by an expert committee, composed not only of narcotic drug specialists, but also physicians, educators, and social workers.

The extent of drug addiction is not known, partly because addiction is a secret vice, and partly because the ethics of the medical profession in many countries do not permit revealing or reporting cases of addiction to the authorities. The estimate of the Commission on Narcotic Drugs, which certainly cannot be regarded as other than conservative, was expressed in the following terms in its report to the Economic and Social Council for its 1956 session: "Drug addicts in the world today still amount to many millions. Established figures of the number of addicts to opium, cannabis, and coca leaves, show millions of addicts to each of them, and addicts to manufactured drugs must be reckoned at at least hundreds of thousands." In this connection, it should be mentioned both that nonmedical or quasimedical use of opium, cannabis, or coca leaves, is still permitted or tolerated in certain countries, and that opium smoking and opium eating were only outlawed by the 1953 protocol. The protocol allows a period of transition which may not extend more than fifteen years beyond 
its effective date. It is to be expected that the projected single convention, with a similar transitional period, will prohibit the nonmedical use of cannabis and coca leaves. It is, however, to be feared, that practical application of these policies will not reach full fruition for many years to come.

Recently, extended consideration has been given in the United States to the suggestion that the problem of drug addiction can satisfactorily be resolved by socalled narcotics clinics, where gradually reduced doses of narcotic drugs would be administered to addicts under medical supervision. This technique was tried in the I920's, however, and abandoned as a complete failure; and to revive and reinstitute it now would be a gravely retrogressive step. It would serve only to maintain addiction and enrich the illegal traffickers from whom the addict would continue to procure the balance of his narcotic drug requirement. Past experience testifies amply to the fact that a cure of narcotic drug addiction is possible only in closed institutions, where the patient is completely shut off from the outside world. The suggested clinics-in fact, any ambulatory method of treatment--would be fatal to this end.

In the meantime, addiction remains a very serious problem, and more attention clearly should be devoted by the principal international organs to its elimination. Governments are now, of course, in their annual reports, supplying the Commission on Narcotic Drugs with many types of information regarding addiction-e.g., number, age groups, professions, drugs used-and this is, no doubt, interesting and useful. But the Commission cannot thus be expected ever to obtain accurate information concerning the extent and nature of addiction. The World Health Organization, however, is studying, through a group of experts methods of medical treatment and rehabilitation of addicts, and these studies may ultimately lead to more useful results. The curing of addicts is, in most cases, possible, but without rehabilitation measures and close supervision, most addicts will relapse into their old ways on return to their normal lives in their habitual surroundings. Rehabilitation and after-care is, therefore, an essential aspect of effectively coping with addiction.

\section{Limitation of Raw Materials}

As long as there is an abundant supply of raw materials that may be used for narcotic purposes or from which narcotic drugs may be manufactured, and as long as there is a demand for illicit narcotic drugs, there will always be supplies for the illicit traffic and for the addict. The suppression of the demand is still a long way off, and so it has become all the more imperative either to devise methods for the limitation of production of raw materials to the world's medical and scientific needs or to establish such stringent controls that no supplies will escape into the illicit traffic. This problem has engaged the attention, first, of the League of Nations, then, of the United Nations, for more than twenty-five years. A satisfactory solution has not yet been found, although, as far as opium is concerned, the $x 953$ protocol represents a forward step. Efforts so far have primarily been concentrated on raw 
opium for two reasons: First, addiction to opium and its derivatives (morphine, heroin, etc.) is the most widespread in the world. Secondly, the opium poppy does not grow wild, but must be cultivated to produce opium-while both the coca leaf and cannabis grow wild-thus affording more promising possibilities for an effective limitation and control.

\section{Raw Opium}

The principal opium producers in recent years have been India, Iran, Turkey, the Soviet Union, and the mainland of China, although Iran has, by a law promulgated in 1955, prohibited all further poppy cultivation and opium production. Smaller quantities have also regularly been produced in Afghanistan, Bulgaria, Greece, Japan, Pakistan, and Yugoslavia. The opium poppy is also cultivated extensively for its seeds, particularly in a number of East European countries. The production of opium requires two conditions which, in fact, limit the areas where it can profitably be pursued: a reasonable certainty of good weather at the time of harvest, as rain may wash away the whole crop; and, as each poppy head must be treated by hand at least twice, an abundant supply of cheap labor.

Reference already has been made to the fact that the Opium Advisory Committee of the League of Nations, in 1940, had prepared a draft convention for the limitation of opium production to the world's medical and scientific needs. Unfortunately, however, the Commission on Narcotic Drugs, in approaching this problem, chose to disregard the League draft and addressed itself, instead, to a new scheme, the central feature of which was an international opium organization, with a monopoly to purchase, stock, and sell raw opium. This scheme was endorsed by the United Nations secretariat and certain members of the Commission, but in view of both the tense international situation and the fact that opium is an important strategic substance, the majority of the Commission was unwilling to place in the hands of an international monopoly the responsibility for the world's supply of opium. The Commission, for other reasons as well, came to view the proposed monopoly with suspicion, and in the end, after years of labor and discussion, the whole scheme was abandoned in 1952 .

At this point, the representative of France outlined a more restricted proposal, which, at the international conference in New York, became the I953 protocol. The protocol does not limit opium production to the world's medical and scientific needs, although it stipulates that the use of opium shall be limited to such needs. A limitation is, however, placed on the stocks that each country may maintain, whether they are producing, drug manufacturing, or purely consuming countries. For producing countries, the annual stocks held on December $3^{\text {rst }}$ of each year must not exceed the amount of opium exported or used for the manufacture of drugs in any two-and-one-half-year period, and production must be regulated so as not to exceed such stocks; manufacturing countries may keep stocks corresponding to two years' normal requirements; and consuming countries, stocks corresponding to the quanti- 
ties used during the preceding five years. Each producing country must, moreover, commit the whole of its opium production and trade to one or more government agencies. There are also a number of detailed rules regarding licensing of cultivators, areas under license, collection of opium, etc. The Permanent Central Opium Board is given various extensive powers in the supervision of the application of the protocol, and these go far beyond its powers under the I925 and r931 conventions. The protocol gives a monopoly of producing opium for export purposes to the following seven countries: Bulgaria, Greece, India, Iran, Turkey, the Soviet Union, and Yugoslavia.

It is obvious that these provisions concerning maximum stocks are very liberal and that if they were fully exploited, world stocks of opium would exceed medical and scientific needs several times over. The protocol thus, does not provide for a real limitation of production to the world's medical and scientific needs. But the protocol was initially intended to be only temporary in character, pending the drafting and the effectuation of the single convention, which, it was hoped, would provide for truly effective limitation. Unfortunately, however, the Commission on Narcotic Drugs has now abandoned further attempts to effect a real limitation and has decided simply to insert the provisions of the I953 protocol, as such, into the draft single convention.

It may be of interest here to review the world situation as regards opium production. It is estimated that the world needs, for medical and scientific purposes, 500 to 600 tons annually, and about 750 tons if the still-permitted quasi medical consumption is included, as it should be, for the transitional period allowed by the r953 protocol. The published statistics of the Permanent Central Opium Board show that production, as reported to the Board, amounted in 1953 to I,294 and in I954 to 773 tons, respectively. The latter figure enabled the Board to state in its annual report for 1955 that in 1954 , production decreased and that licit requirements increased and exceeded production. This statement should, however, be seen in the light of the following facts:

x. All large producers (India, Iran, Turkey, but not the Soviet Union) reported much smaller crops in 1954 than in 1953. This might have been attributable to a reduction of area under cultivation (e.g., India), but more likely reflects a partial crop failure, which is not uncommon.

2. In the same report of the Permanent Central Opium Board, there was published a statement of the Health Minister of Iran, issued at a press conference in Teheran, on August 4, r955, to the effect that actual production in Iran was from 700 to $I, 200$ tons a year, whereas the production reported to the Permanent Central Opium Board was 227 tons in 1953 and 145 in 1954, respectively.

3. The Board's report makes no mention of the production on the mainland of China, presumably because the Board receives no official statistics from the People's Democratic Republic of China, where opium production is supposed to be illegal. That such production exists, however, is evidenced by the proceedings of the Commission on Narcotic Drugs year after year, from which it appears that production 
on the mainland of China alone may amount to as much as two to three times the licit production of the rest of the world. A large part of this opium finds its way into the international illicit traffic, either as raw opium or as morphine or heroin manufactured on the mainland of China. Accordingly, the statement that world's licit requirements exceed world's production is clearly misleading and dangerous, although the figures the Board possesses may seem to furnish a justification.

The future of opium on licit world markets is not bright. Demands for nonmedical consumption will disappear within a few years if the I953 protocol comes into full force. Moreover, twenty to twenty-five per cent of the world's production of morphine today is obtained by extraction from poppy straw; and the expanding use of synthetic drugs has made further inroads into the licit demand for opium. It is true that the consumption of opium derivatives is constantly increasing with the extension and improvement of health services. The time may, however, come in the near future when the world will require much less opium than it does today; and producing countries which do not wish to feed their opium to the illicit traffic will then have to reduce their production and replace opium with other crops. This should be an internationally regulated process, and it is, therefore, deeply to be regretted that the Commission on Narcotic Drugs, and, thus, also the United Nations, has abandoned the plan of elaborating an effective scheme for limitation of opium production.

The problem is, admittedly, not easy, as the producing countries see no justification for sacrificing the livelihood of their peasants in favor of poppy straw and synthetic drugs. The other side, however, is not willing to forego the use of either poppy straw for extraction of morphine or synthetic drugs. Nevertheless, with some good will and energy, it should be possible to arrive at a compromise between these competing interests, to the benefit of humanity as a whole.

\section{The Coca Leaf}

Cocaine, a narcotic drug derived from the coca leaf, has not generally been considered to present a serious international problem. The Commission on Narcotic Drugs has recently noted certain indications that cocaine addiction may be on the increase, however, and this situation, accordingly, requires careful watching.

The cóca bush is cultivated and also grows wild in certain South American countries-namely, Bolivia, Colombia, and Peru. There is also some cultivation in Indonesia and on Formosa. The Permanent Central Opium Board reported world production in 1954 to be some 13,000 tons, although only 700 tons are used annually for medical purposes-i.e., for the manufacture of cocaine. The rest is accounted for by quasi medical consumption-i.e., the chewing of coca leaves, a habit prevalent among the indigenous populations of Argentina, Bolivia, Colombia, and Peru. Colombia, it should be noted, has, for some years, pursued an active policy of suppressing this last-mentioned habit, and the governments of the other three countries have declared their intention of doing likewise. Accordingly, the Commission on 
Narcotic Drugs has recently decided that production or harvesting of coca leaves should be limited to the world's medical and scientific needs, and provisions to that effect have been inserted in the draft single convention. These provisions are largely modeled on those of the r 953 opium protocol.

\section{Cannabis}

More commonly known as Indian hemp, this is an industrial plant that is widely cultivated for its textile fibres and its seeds. The plant contains an alkaloid (cannabinol) that has certain narcotic properties and is extensively used for nonmedical consumption in many different forms. Most potent and dangerous is the resin formed by the plant under certain climatic conditions. This resin is used in many parts of the world, under many different names-e.g., charas, bhang, hashish, takrouri, chiras, djamba, and esrar. On the American continent, cannabis is most widely known as marijuana, and this substance usually contains dried leaves of the plant, which is made up with tobacco into cigarettes. Although cannabis has very violent effects and may cause insanity or homicidal tendencies, its nonmedical use is still tolerated in some Asiatic countries.

The existing international drug conventions contain very little in regard to cannabis. There are some relevant provisions in the 1925 convention, but these apply only to the dried, flowering, or fruiting tops of the pistulate plant from which the resin has not been extracted and to the resin itself. The international trade is controlled through the import certificate and export authorization system, however, and there are certain special prohibitions on the export of resin and its preparations. And the 1936 convention for the suppression of the illicit narcotic drug traffic also applies to Indian hemp, as defined in the 1925 convention.

The League of Nations devoted much interest and time to the cannabis problem. It had a permanent subcommittee on cannabis, composed of outstanding international experts. The United Nations Commission on Narcotic Drugs, however, has only in recent years taken an active interest in cannabis-except for the illicit traffic aspects, which come up for discussion every year-and at present deals with two aspects of the general problem: the possibility of developing a narcotic-free strain of the cannabis plant, and the replacement of the plant by nonnarcotic plants that would produce similar textile fibres. The Commission is assisted in these quests by the Food and Agricultural Organization and by various governments. Neither of these lines of inquiry, interesting as they may be, however, appears to promise success within the immediately foreseeable future, let alone the enormous practical difficulties that will be encountered in trying to replace the actual hemp plant by a narcotic-free strain or by another nonnarcotic plant. Accordingly, the Commission has now decided to include in the single convention special provisions prohibiting cannabis, except for the purpose of scientific research (production, trade, possession, and use), but these will refer only to the alkaloid contained in the plant, its resin, 
and all substances containing the pharmacologically active principle of cannabis. There is, of course, no question of limiting or controlling the cultivation of the plant.

VI

\section{The Single Convention}

The need for codification of the international narcotic drug instruments is, perhaps, now more easily understood. This idea was initiated during the days of the League of Nations and was taken up by the Commission on Narcotic Drugs at an early date. After many years of work and discussion, there has now been produced a second draft that is practically complete and that was considered by the Commission at its 1956 session. In this draft, however, the Commission has made no final proposals on several points, but has, instead, inserted various alternatives. The present text cannot, accordingly, be submitted to an international conference. At its last session, therefore, the Commission reached two procedural decisions: first, to communicate the second draft for observations to governments represented on the Commission and to such other governments whose observers had taken part in the preparation of the draft; and, secondly, to appoint a committee of five members to meet before the next session of the Commission for the purpose of preparing, in the light of observations of governments, a simplified draft, removing as many of the alternatives as possible. This new draft is to be considered by the Commission at its 1957 session.

Some members of the Commission on Narcotic Drugs have been critical of the slow progress that has been made in formulating the single convention and have urged greater dispatch. Other members appear somewhat disinterested, however, and may deliberately be playing delaying tactics. Under these circumstances, therefore, it may take another ten years before the single convention has been concluded and brought into force.

Codification is certainly a difficult task, but not so complicated as to require fifteen years or more work. There are two valid reasons, however, for hesitating to push the single convention: First, there is a risk that the new convention may not be as strict as the old instruments-i.e., in codification, important provisions may be omitted or attenuated. For example, in 1953, the Commission on Narcotic Drugs discovered that the text before it lacked the very important provisions for limitation of manufacture, one of the essential features of the 193r convention. This difficulty is, of course, not insurmountable and may be obviated by submitting the final draft to a special committee of narcotic drug experts and international lawyers for the purpose of verifying the text from this point of view. Second, there is the notorious slowness in ratification of treaties. A case in point is the 1953 opium protocol, whose coming into force is not yet in sight after more than three years. The League of Nations showed what could be done with determination and effort, however, when the 193I convention was brought into force within two years of its conclusion, and 
this despite the fact that the convention entailed a most radical departure in international law affecting the sovereignty of states. Nevertheless, it may take many years before the single convention will have received as wide application as the conventions of I9I2, I925, and I93I, and in the meantime, there will be nine instead of eight international instruments, and the confusion may be worse than it is today.

Attention should be drawn to the fact that the present draft so greatly extends and strengthens the powers of the international control organs and constitutes such an invasion of the sovereignty of states that many states may hesitate to ratify the convention or may find it impossible to do so because of a conflict with their own constitutions. It may be necessary, therefore, to strike a reasonable compromise between the legitimate desire to enable international control organs to proceed effectively with sanctions against serious violations of the convention and what is legally and practically possible for governments to accept. Universality of application is essential, and most governments will show good will in fulfilling their obligations. For the exceptional cases of serious violations, the present powers of the Permanent Central Opium Board and the attending world-wide publicity should be quite sufficient to meet any critical situation.

\section{VII}

\section{The Efricacy of Control}

Through the international instruments and the work of the Opium Advisory Committee and the Commission on Narcotic Drugs, control has been effected on a world-wide scale. The conventions, and particularly the limitation convention of I93I, represent the first concerted attempt by governments to regulate a single industry throughout the world, from the point at which the raw materials enter the international trade to the point at which they finally reach the legitimate consumer. The essential elements of this control may be summed up as follows: the determination in advance of legitimate world needs; the adjustment of world manufacture to legitimate world demand; the minute controlling of all channels of distribution, both national and international; and the entrusting to international organs of the task of supervising and coordinating the working of the whole machinery throughout the world. Nothing similar or as far-reaching in international cooperation has ever been attempted. The Assembly of the League of Nations described the limitation convention of $193 \mathrm{I}$ as embodying "a bold conception, without precedent in the history of international relations and international law." In 1934, the League Assembly stated that the convention had set up "a real international administration." Not only have governments accepted extensive and binding obligations, but they have countenanced pervasive encroachment on their national sovereignty-and these limitations of sovereignty have affected not only parties to the convention, but also nonsignatory countries. Every transaction, whether it be in raw materials or manufactured narcotic drugs, is subject to national control of the strictest kind, and govern- 
ments, in their turn, are continuously supervised by and are responsible to the international control organs.

The control system is unquestionably effective as far as it goes, but it must always be remembered that its success depends ultimately on governments-on their goodfaith fulfillment of their obligations and on their administrative efficiency. The question arises why, with the existence of this control, there still is illicit traffic and narcotic drug addiction. The reply must be that, in the first place, as outlined earlier, raw materials have not yet been sufficiently controlled. In the second place, despite the efficiency of administration and control, there are always dishonest people who are tempted by the enormous profits of the illicit traffic. The facts revealed-as regards the production in Iran, for example-prove that despite control, raw opium has been produced in quantities much larger than those collected by or delivered to the government; and such raw opium almost invariably enters into the illicit traffic. As all licensed drug factories are strictly supervised, traffickers resort to clandestine manufacture, and the Commission on Narcotic Drugs has found that in recent years, such manufacture usually takes place near the sources of raw materials. The third reason is that, by reason of their small bulk, narcotic drugs are readily smuggled and easily escape the attention of police and other enforcement officials.

The fact that illicit traffic and addiction continue is, however, no reason to condemn the national and international control system, without which it is certain that illicit narcotic drug traffic and addiction would be far more widespread and would constitute a far greater menace to the whole world. Governments and the international organizations must, instead, continue the struggle and make every effort to tighten the net, so as to choke off the channels through which this illicit traffic flows and mitigate the ravages it causes.

\section{VIII}

\section{The Future}

An attempt has here been made to describe the international narcotic drug control system and to point out its existing weaknesses as well as its strength. To remedy these weaknesses, the United Nations, through its appropriate organs, must undertake a full review of the present work, procedures, and plans for the future. If such a review is not undertaken shortly, there is great danger that the international control machinery may hopelessly deteriorate. A new deal, a new approach, is called for, particularly as regards the Commission on Narcotic Drugs. In view of the difficulties experienced by the Commission in expeditiously discharging its functions, its entire role and organization should be carefully restudied. As the Commission frequently is frustrated by political and national interests, something should be done to neutralize those influences. Naturally, governments could do much to alleviate the situation by assigning to the Commission their experienced experts, with instructions to work toward the professed common goal, ignoring, as far as possible, incidental political 
and economic considerations. One technique might be to have a special body of independent experts prepare the work of the Commission and propose to the Commission the solutions appropriate in each case. This body could be comparatively small, and the present Permanent Central Opium Board might well operate satisfactorily in this capacity. This would require a revision of the existing conventions, however, and it could be accomplished by the proposed single convention. The Board would then, of course, have to be a permanent body, and its members remunerated sufficiently well to guarantee their independence and impartiality.

In this last connection, the United Nations should see to it that lack of funds does not hamper progress. The campaign against the illicit narcotic drug traffic is costing the world millions of dollars annually in direct expenses, not to mention the untold millions of dollars of economic loss to society entailed by the existence of millions of addicts whe are unable to work and produce effectively.

No country, be its laws ever so drastic and their enforcement ever so effective, can alone protect itself and its people against the scourge of narcotic drugs. There is only one way to success, and that is through effective international action and cooperation-which today means through the United Nations and its organs. There is no other alternative. The peoples of the world are, accordingly, looking to the United Nations for a solution. It must not fail them. 